\title{
Nerve Conduction Studies of Median Motor Nerve and Median Sensory Branches According to the Severity of Carpal Tunnel Syndrome
}

\author{
Hye Jin Lee, $\mathrm{MD}^{1}$, Hee Kyu Kwon, $\mathrm{MD}^{2}$, Dong Hwee Kim, $\mathrm{MD}^{2}$, Sung Bom Pyun, $\mathrm{MD}^{2}$ \\ ${ }^{1}$ Department of Physical Medicine and Rehabilitation, National Rehabilitation Center, Seoul; \\ ${ }^{2}$ Department of Physical Medicine and Rehabilitation, Korea University College of Medicine, Seoul, Korea
}

Objective To evaluate each digital branch of the median sensory nerve and motor nerves to abductor pollicis brevis (APB) and 2nd lumbrical (2L) according to the severity of carpal tunnel syndrome (CTS).

Methods A prospective study was performed in 67 hands of 41 patients with CTS consisting of mild, 23; moderate, 27; and severe cases, 17. Compound muscle action potentials (CMAPs) were obtained from APB and 2L, and median sensory nerve action potentials (SNAPs) were recorded from the thumb to the 4th digit. Parameters analyzed were latency of the median CMAP, latency difference of $2 \mathrm{~L}$ and first palmar interosseous (PI), as well as latency and baseline to peak amplitude of the median SNAPs.

Results The onset and peak latencies of the median SNAPs revealed significant differences only in the 2nd digit, according to the severity of CTS, and abnormal rates of the latencies were significantly lower in the 2nd digit to a mild degree. The amplitude of SNAP and sensory nerve conduction velocities were more preserved in the 2nd digit in mild CTS and more affected in the 4 th digit in severe CTS. CMAPs were not evoked with APB recording in 4 patients with severe CTS, but obtained in all patients with 2L recording. 2L-PI showed statistical significance according to the severity of CTS.

Conclusion The branch to the 4th digit was mostly involved and the branch to the 2nd digit and 2L were less affected in the progress of CTS. The second digit recorded SNAPs and 2L recorded CMAPs would be valuable in the evaluation of severe CTS.

Keywords Carpal tunnel syndrome, Median nerve, Nerve conduction study, Digital branch of median nerve

Received November 9, 2011; Accepted September 12, 2012

Corresponding author: Hee Kyu Kwon

Department of Physical Medicine and Rehabilitation, Korea University College of Medicine, 73 Inchon-ro, Seongbuk-gu, Seoul 136-705, Korea

Tel: +82-2-920-6480, Fax: +82-2-920-9951, E-mail: hkkwon@korea.ac.kr

(a) This is an open-access article distributed under the terms of the Creative Commons Attribution Non-Commercial License (http://creativecommons. org/licenses/by-nc/3.0) which permits unrestricted noncommercial use, distribution, and reproduction in any medium, provided the original work is properly cited.

Copyright $\odot 2013$ by Korean Academy of Rehabilitation Medicine

\section{INTRODUCTION}

Carpal tunnel syndrome (CTS) is a neuropathy caused by entrapment of the median nerve at the wrist, which leads to pain, hypesthesia at the dermatome area and weakness of the abductor pollicis brevis (APB) muscle [1]. It is the most common peripheral neuropathy and Atroshi et al. [2] reported that it occurs in $5.8 \%$ of women and $0.6 \%$ of men.

Diagnosis of CTS is made with clinical symptoms, phys- 
ical examination and electrodiagnostic study, of which, electrodiagnostic study is known to be the most accurate and useful method of diagnosis [3,4]. However, a variety of study methods exist to increase the sensitivity, and every physician has his own preferred method. Measuring the differences in peak, onset latency and baseline to peak amplitude between stimulation at the wrist, where a $14 \mathrm{~cm}$ proximal to the recording electrode and at the palm, $7 \mathrm{~cm}$ proximal to the electrode, and comparing latencies with ulnar and radial sensory nerve are the general methods recommended by the American Association of Neuromuscular Electrodiagnostic Medicine [5,6]. In most cases, the 2nd or 3rd finger is used for recording electrodes in a median nerve sensory conduction study $[3,5]$. However, the debate in which the finger is most sensitive for the diagnosis of CTS is still ongoing [7-9].

Sheean et al. [6] reported that the onset latency of median motor conduction studies recorded on APB is less sensitive than other electrodiagnostic parameters in CTS diagnosis, and that it would be useful to compare the onset latencies of compound muscle action potentials (CMAP) of the median innervated lumbrical muscles and ulnar innervated interosseous muscles in the palm. Boonyapisit et al. [10] also reported that for a moderate degree of CTS, it is helpful to use a lumbrical recording for localization of the lesion and differential diagnosis from other conditions, such as polyneuropathy, when action potential is not evoked due to atrophy of APB.

In this study, we evaluated the median sensory nerve action potentials (SNAP) from each digit and CMAP onset latency differences between the 2nd lumbrical muscle and interosseous muscle for each CTS severity to observe the involvement of median sensory and motor nerve branches, according to disease progression.

\section{MATERIALS AND METHODS}

\section{Materials}

A prospective study was performed on 67 hands of 41 patients who visited Korea University Hospital for tingling sensation, pain and hypesthesia at the median nerve dermatome and were diagnosed with CTS in an electrodiagnostic study. The average age was $56.2 \pm 11.2$ years with 9 males (14 hands) and 32 females (53 hands). Patients with peripheral polyneuropathy, ulnar neuropathy, and cervical radiculopathy were excluded. Patients who had received surgical management for diagnosed CTS were also excluded. To obtain the criteria for amplitude ratios of the sensory nerve conduction study, 21 control subjects without any clinical symptoms or history of surgical management were also evaluated.

\section{Methods}

Counterpoint Mk2 (Dantec, Skovlunde, Denmark) was used for the electrodiagnostic study. An antidromic method was used for the sensory nerve conduction study. For the median sensory conduction study, an active electrode was placed on the proximal phalanx at each of the 1 st to 4 th digits, and the reference electrodes were placed $4 \mathrm{~cm}$ distal to each active electrode. Stimulation was applied at $10 \mathrm{~cm}$ proximal [11] to the active electrode for the 1st digit, and $14 \mathrm{~cm}$ proximal to the $2 \mathrm{nd}$, 3rd, and 4th digits. For the ulnar sensory conduction study, active, and reference electrodes were placed at the $4 \mathrm{~h}$ and 5 th digits, and stimulation was applied at the wrist $14 \mathrm{~cm}$ proximal to the active electrode. For every SNAP, the onset latency, peak latency, baseline to peak amplitude, and conduction velocity was measured. The median nerve peak latencies of over $3.7 \mathrm{~ms}$ at $2 \mathrm{nd}$, 3rd, and 4th digits, were considered as prolonged latency.

For the motor conduction study, an active electrode was placed at the middle portion of the APB muscle and stimulation was applied at the wrist, $8 \mathrm{~cm}$ proximal to the active electrode and at the elbow. Onset latency, amplitude and conduction velocity were obtained. Preston's method [12] was used for the lumbrical and 2nd interosseous muscle recordings. An active electrode was placed at the lateral portion of the 3rd metacarpal bone, as well as a reference electrode at the 2 nd metacarpal joint. Stimulation was applied at the wrist $10 \mathrm{~cm}$ proximal to the active electrode for the median and ulnar nerve.

Criteria using the 3rd digit, revised by the author, were used for CTS severity classification. For the 2nd digit, the same criteria were applied for the onset latency, peak latency, and baseline to the peak amplitude and conduction velocities. For the 4th digit, amplitude was excluded from the criteria (Table 1) [13]. For the 1st digit, considering the difference in distance between the electrodes from the other digits, latency difference according to the severity was evaluated within the 1st digit, and the sensory conduction velocity was compared with the 2 nd, 3rd, and 4 th digits. For the median motor conduction study, 
Table 1. Severity of carpal tunnel syndrome [13] (Revised by the author)

\begin{tabular}{|c|c|c|c|}
\hline Severity & Sensory NCS & Motor NCS & APB needle EMG \\
\hline $\begin{array}{l}\text { Mild: at least } 3 \text { of the } \\
\text { following sensory } \\
\text { and motor nerve } \\
\text { conduction }\end{array}$ & $\begin{array}{l}\text { 1) } 14 \mathrm{~cm} \text { wrist stimulation; peak latency, }>3.7 \\
\text { ms } \\
\text { 2) } 14 \mathrm{~cm} \text { wrist stimulation; the peak latency, } \\
\text { proximal } 7 \mathrm{~cm}>\text { distal } 7 \mathrm{~cm} \\
\text { 3) Transcarpal } 5 \mathrm{~cm} \text { short-segment latency } \\
\text { (proximal latency-distal palm latency): } \\
\text { onset }>1.3 \mathrm{~ms} \text {, peak }>1.5 \mathrm{~ms} \\
\text { 4) } 14 \mathrm{~cm} \text { wrist stimulation SNAP amplitude, } \\
16-20 \mu \mathrm{V}\end{array}$ & $\begin{array}{l}\text { 5) Distal latency, }>4.2 \\
\text { ms } \\
\text { 6) APB CMAP ampli- } \\
\text { tude, } 4.1-4.5 \mathrm{mV}\end{array}$ & Normal \\
\hline $\begin{array}{l}\text { Moderate: mild plus } \\
\text { at least } 2 \text { of the fol- } \\
\text { lowing }\end{array}$ & $\begin{array}{l}\text { 1) } 14 \mathrm{~cm} \text { wrist stimulation SNAP amplitude, } \\
6-15 \mu \mathrm{V} \\
\text { 2) Conduction block greater than } 50 \% \text { at wrist } \\
\text { \& palm stimulation if SNAP } \geq 10 \mu \mathrm{V} \text { with } 14 \\
\mathrm{~cm} \text { wrist stimulation }\end{array}$ & $\begin{array}{l}\text { 3) CMAP amplitude, } \\
2.1-4 \mathrm{mV}\end{array}$ & $\begin{array}{l}\text { 4) Fibrillation }( \pm) \\
\text { 5) Abnormal MUAP } \\
\text { with intermediate } \\
\text { interference pat- } \\
\text { terns }\end{array}$ \\
\hline $\begin{array}{l}\text { Severe: moderate } \\
\text { plus }\end{array}$ & 1) SNAP amplitude, $\leq 5 \mu \mathrm{V}$ & $\begin{array}{l}\text { 2) CMAP amplitude, } \\
\leq 2 \mathrm{mV}\end{array}$ & $\begin{array}{l}\text { 3) Fibrillations }(+) \\
\text { 4) Abnormal MUAP } \\
\text { with discrete activi- } \\
\text { ties or single unit } \\
\text { patterns }\end{array}$ \\
\hline
\end{tabular}

NCS, nerve conduction study; APB, abductor pollicis brevis; EMG, electromyography; CMAP, compound motor action potentials; SNAP, sensory nerve action potentials; MUAP, motor unit action potentials.

an onset latency over $4.2 \mathrm{~ms}$ and lumbrical-interosseous latency difference over $0.4 \mathrm{~ms}$ were considered as abnormal [6].

Parameters analyzed in the median sensory conduction study were onset latency, peak latency, baseline to peak amplitude and conduction velocity from each digit. In analyzing SNAP amplitude, due to a considerable number of bilateral CTS, amplitude ratios of the median SNAP from the 2nd and 3rd digits to ulnar SNAP from the 5th digit were obtained. Due to dual innervation at the 4th digit, the median SNAP amplitude was small even in normal subjects. Hence, amplitude ratios to the ulnar SNAP at the 4th digit were obtained. For amplitude ratio analysis, criteria obtained from the receiver operating characteristic (ROC) curve was compared with the patient group. Frequency of abnormal values for amplitude ratio was evaluated. Criteria for the 2nd and 3rd digit were 0.8 and for the 4 th digit was 0.83 , respectively. Due to the short distance between the electrode and the stimulation site, amplitude comparison was made only between the 2nd, 3rd, and 4th digits, and the 1st digit was excluded. For median CMAP parameters, onset latency from APB, 2nd lumbrical muscle and lumbrical-interosseous latency differences were analyzed. For the subjects with unevoked potentials, predictive values for onset latency and conduction velocity, corresponding to an amplitude value of ' 0 ' using regression analysis was used as a substitute value [14].

SPSS ver. 12.0 (SPSS Inc., Chicago, IL, USA) was used for statistical analysis. Age difference and comparison with the control group according to the CTS severity was analyzed using one-way analysis of variance (ANOVA) test and Tukey test for the post hoc study. For other discrete variables, the chi-square test or Fisher exact test was used. Changes in the median SNAPs of the four digits, according to the CTS severity were analyzed using repeated measures of ANOVA. Criteria were obtained with an amplitude ratio of the control group, using the ROC curve. Based on the criteria, the frequencies of which abnormal values appear for each digit were analyzed in the patient group. A p-value less than 0.05 was considered to be statistically significant.

\section{RESULTS}

Among the 67 hands of the 41 patients diagnosed with CTS, 23 were of mild degree, 27 moderate, and 17 were severe degree. The average age of the entire CTS patient 
group was $56.2 \pm 11$ years, and $55.7 \pm 9.8$ years in the mild degree group, $55.0 \pm 8.9$ years in the moderate degree group, $59.3 \pm 9.1$ years in the severe degree group, and $53.3 \pm 12.2$ years in the control group. The female ratio was higher in both the patient and the control groups. No statistical significance was observed with regard to which hand was involved. There were no differences with respect to age according to the CTS severity (Table 2).

\section{Median SNAP latency comparison}

The average onset and peak latency of the patient group for each digit were: $3.95 \pm 2.55$ and $4.20 \pm 2.89 \mathrm{~ms}$ for the 1st digit, $4.35 \pm 2.21$ and $5.53 \pm 2.89 \mathrm{~ms}$ for the $2 \mathrm{nd}$ digit, $4.98 \pm 3.44$ and $5.94 \pm 3.02 \mathrm{~ms}$ for the 3rd digit, and $5.09 \pm 2.62$ and $5.97 \pm 3.15 \mathrm{~ms}$ for the 4 th digit, respectively. Of the three digits with the same distance between an electrode and the stimulation site, the $2 \mathrm{nd}$, 3rd, and 4 th digits, the latency of the second digit was shorter with statistical significance $(\mathrm{p}<0.05)$, where the 4 th digit showed the most prolonged latency without statistical significance. Onset and peak latency differences according to the CTS severity for each digit showed statistical

Table 2. Demographic and clinical characteristics of patients

\begin{tabular}{|c|c|c|c|c|c|}
\hline \multicolumn{2}{|c|}{ Characteristic } & \multirow{2}{*}{$\begin{array}{c}\begin{array}{c}\text { Mild } \\
\text { (23 hands) }\end{array} \\
55.7 \pm 9.8\end{array}$} & \multirow{2}{*}{$\begin{array}{c}\begin{array}{c}\text { Moderate } \\
\text { (27 hands) }\end{array} \\
55.0 \pm 8.9\end{array}$} & \multirow{2}{*}{$\begin{array}{c}\begin{array}{c}\text { Severe } \\
\text { (17 hands) }\end{array} \\
59.3 \pm 9.1\end{array}$} & \multirow{2}{*}{$\begin{array}{c}\begin{array}{c}\text { Normal } \\
\text { (30 hands) }\end{array} \\
53.3 \pm 12.2\end{array}$} \\
\hline Age (yr) & & & & & \\
\hline \multirow[t]{2}{*}{ Gender } & Male & 2 & 6 & 6 & 8 \\
\hline & Female & $21^{\text {a) }}$ & $21^{\text {a) }}$ & $11^{\mathrm{a})}$ & $22^{a)}$ \\
\hline \multirow[t]{2}{*}{ Side } & Right & 12 & 16 & 11 & 15 \\
\hline & Left & 11 & 11 & 6 & 15 \\
\hline
\end{tabular}

${ }^{a)} \mathrm{p}<0.05$, significant differences exists in the number of hands between male and female in each group.

Table 3. Onset and peak latency of median SNAP according to the severity of CTS

\begin{tabular}{|c|c|c|c|c|}
\hline \multirow{2}{*}{ Digit } & \multirow{2}{*}{ Degree of CTS } & \multicolumn{3}{|c|}{ Median SNAP } \\
\hline & & Mean OL (ms) & Mean PL (ms) & Abnormal rate (\%) \\
\hline \multirow[t]{4}{*}{ I } & Mild & $2.79 \pm 0.54$ & $3.33 \pm 0.64$ & - \\
\hline & Moderate & $3.41 \pm 0.63$ & $4.19 \pm 0.80$ & - \\
\hline & Severe & $7.01 \pm 2.56^{\mathrm{a})}$ & $8.02 \pm 4.19^{a)}$ & - \\
\hline & Total & $3.95 \pm 2.55$ & $4.20 \pm 2.89$ & - \\
\hline \multirow[t]{4}{*}{ II } & Mild & $3.48 \pm 0.36^{\text {a) }}$ & $3.98 \pm 0.45^{\mathrm{a})}$ & $86^{\mathrm{a}, \mathrm{b})}$ \\
\hline & Moderate & $3.98 \pm 0.77^{\mathrm{a})}$ & $4.83 \pm 0.84^{\mathrm{a})}$ & 92 \\
\hline & Severe & $7.13 \pm 3.28^{\mathrm{a})}$ & $8.28 \pm 1.83^{\mathrm{a})}$ & 100 \\
\hline & Total & $4.35 \pm 2.21^{\mathrm{a}, \mathrm{b})}$ & $\left.5.53 \pm 2.89^{\mathrm{a}, \mathrm{b}}\right)$ & 92 \\
\hline \multirow[t]{4}{*}{ III } & Mild & $3.60 \pm 0.41$ & $4.37 \pm 0.46$ & 100 \\
\hline & Moderate & $4.15 \pm 0.70$ & $5.11 \pm 0.88$ & 100 \\
\hline & Severe & $7.02 \pm 2.52^{\mathrm{a})}$ & $8.92 \pm 2.60^{\mathrm{a})}$ & 100 \\
\hline & Total & $4.98 \pm 3.44$ & $5.94 \pm 3.02$ & 100 \\
\hline \multirow[t]{4}{*}{ IV } & Mild & $3.73 \pm 0.57$ & $4.52 \pm 0.62$ & 100 \\
\hline & Moderate & $4.28 \pm 0.77$ & $5.21 \pm 0.93$ & 100 \\
\hline & Severe & $8.45 \pm 2.26^{a)}$ & $9.05 \pm 1.88^{\mathrm{a})}$ & 100 \\
\hline & Total & $5.09 \pm 2.62$ & $5.97 \pm 3.15$ & 100 \\
\hline
\end{tabular}

Values are presented as mean \pm standard deviation. Criteria for abnormal latency were $3.7 \mathrm{~ms}$ in digit II, III, and IV. Abnormal rate refers to the frequency of delayed peak latency.

SNAP, sensory nerve action potentials; CTS, carpal tunnel syndrome; OL, onset latency; PL, peak latency.

${ }^{a)} \mathrm{p}<0.05$, comparison according to the severity in each digit. ${ }^{\text {b) }} \mathrm{p}<0.05$, comparison between the 4 digits in each degree. 
differences in mild, moderate, and severe degree groups for the 2 nd digit $(\mathrm{p}<0.05)$. For the 1st, 3rd, and 4th digits, only the moderate degree group showed a significant latency prolongation $(\mathrm{p}<0.01)$. In the $2 \mathrm{nd}$ digit, frequency of peak latency prolongation was significantly lower in the mild group compared to the moderate and the severe groups $(\mathrm{p}<0.05)$. In the 3rd and 4 th digits, latency was prolonged in all CTS degree groups and the frequency of latency prolongation was significantly lower in the 2nd digit compared to the 3rd and 4th digits $(\mathrm{p}<0.01)$ (Table 3 ). Among the patients diagnosed with severe CTS, SNAP was not evoked on the 1st, 3rd, and 4th digits on 8 hands. On 6 of the 8 hands, SNAP was not evoked on the 1st, 2nd, 3rd, and 4th digit, yet 2 hands evoked SNAP on the 2nd digit.

\section{Median SNAP amplitude comparison}

All the digits showed a decrease in the median SNAP amplitude according to the disease severity $(\mathrm{p}<0.05)$. However, in the comparison of amplitude ratios according to the disease severity, only the 4 th digit showed significant amplitude ratio differences between the mild, moderate, and severe groups ( $\mathrm{p}<0.05)$. The 2 nd and 3rd digits showed decreases in amplitude ratios with the dis- ease severity, without statistical significance. In comparing the median nerve amplitude ratios between the digits for each severity, the 2nd digit ratio was significantly larger in the mild group $(\mathrm{p}<0.01)$ and the 4 th digit ratio was significantly smaller in the severe group $(p<0.01)$. Criteria obtained from the amplitude ratios of the control group were 0.89 and 0.88 for the 2nd and 3rd digits, and 0.86 for the 4 th digit. The frequency of abnormal amplitude ratios in the patient group were $75 \%$ for the 1 st, $81 \%$ for the 2nd and 3rd digits in the mild group, which was significantly lower than for the moderate and the severe groups $(\mathrm{p}<0.05)$. In a comparison between digits, frequency was lowest with the 2nd digit and highest in the 4th digit, without any statistical significance (Table 4).

\section{Comparison of median nerve conduction velocity}

By comparison, a significant decrease in conduction velocity according to the disease severity was observed in all the digits $(\mathrm{p}<0.05)$. Comparing the digits for each severity, the conduction velocity was preserved more with the 2 nd digit in the mild degree group $(\mathrm{p}<0.05)$ and more impaired with the 4 th digit in the severe group $(\mathrm{p}<0.05)$. The conduction velocity of the 1 st digit was decreased compared to the other groups in the patient group, with-

Table 4. Amplitude ratio of median SNAP to ulnar SNAP according to the severity of CTS

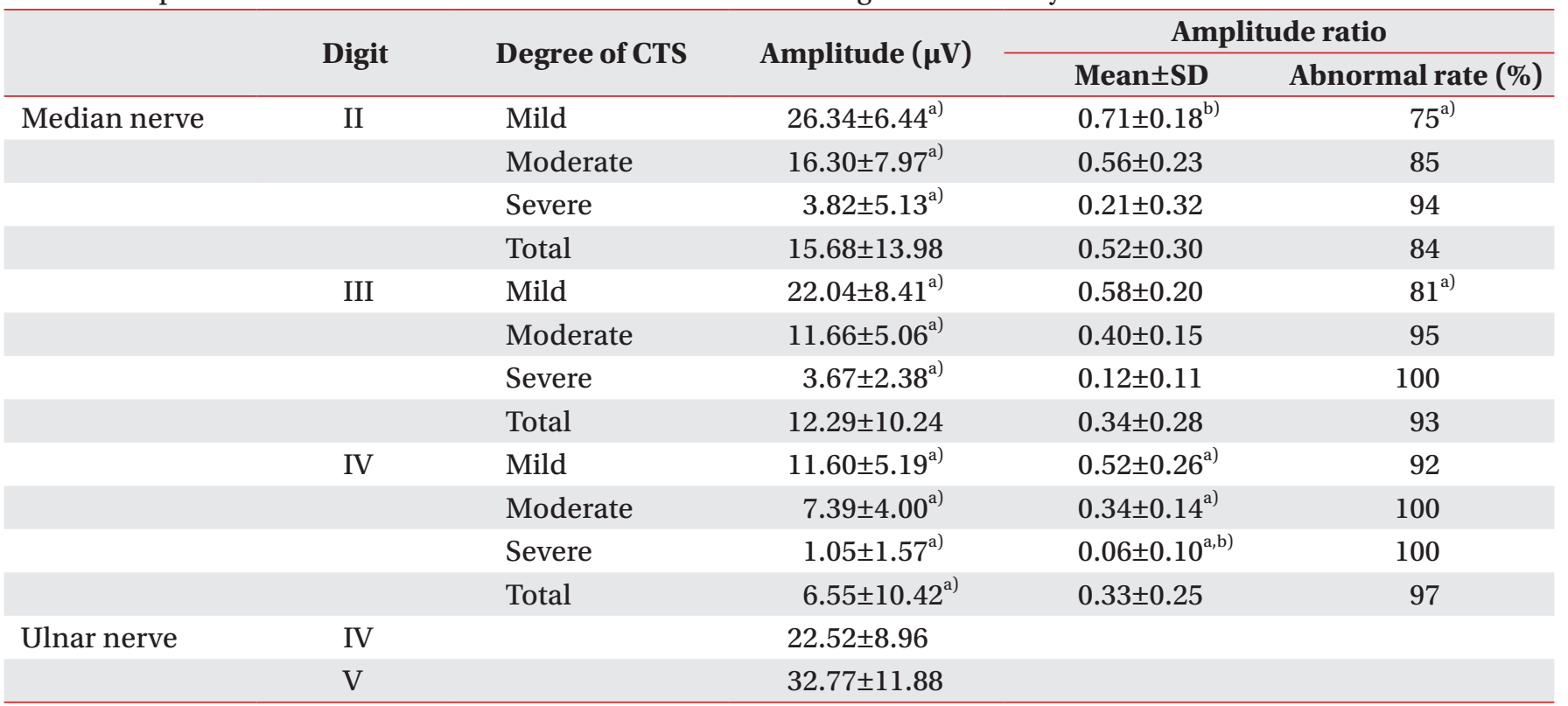

Values are presented as mean \pm standard deviation. Criteria for abnormal amplitude ratio were obtained from the control: 0.89 , 2nd digit; 0.88, 3rd digit; 0.86, 4th digit. Amplitude ratio is median SNAP from 2nd and 3rd digit/ulnar SNAP from 5th digit, and median SNAP from 4th digit/ulnar SNAP from 4th digit.

SNAP, sensory nerve action potentials; CTS, carpal tunnel syndrome.

a) $p<0.05$, comparison according to the severity in each digit. ${ }^{\text {b) }} \mathrm{p}<0.01$, comparison of digit in each degree. 
out statistical significance (Table 5).

\section{Comparison of median CMAP}

The onset latency of APB recording and lumbrical muscle recording was significantly prolonged in the severe group compared to the mild and moderate degree groups. Frequencies of onset latency prolongation in the APB recording were $60 \%, 85 \%$, and $94 \%$ in the mild, moderate, and severe groups, respectively. Frequency in the mild group was significantly lower. Lumbrical-interosseous latency difference was $2.68 \pm 1.29 \mathrm{~ms}$ in the mild group and $2.55 \pm 1.38 \mathrm{~ms}$ in the moderate group, showing no significant difference. However, in the severe group, the latency difference was $4.09 \pm 3.87 \mathrm{~ms}$ with statistical significance compared to the other groups $(\mathrm{p}<0.05)$. The frequency of latency differences longer than $0.4 \mathrm{~ms}$ were $81 \%, 84 \%$, and $92 \%$ in the mild, moderate, and severe group, respectively. The frequencies showed a tendency to rise according to the severity, buy without any statistical significance. In the mild group, frequency of lumbrical-interosseous latency differences longer than $0.4 \mathrm{~ms}$ were significantly higher than the frequency of APB recording latency, longer than $4.2 \mathrm{~ms}(\mathrm{p}<0.05)$. In the moderate and severe groups, no difference was observed between the two frequencies. In the 4 digits, whose CMAPs were not evoked with the APB recording, CMAPs were all observed with a lumbrical recording (Table 6).

\section{DISCUSSION}

An electrodiagnostic study is used as an objective and accurate tool in diagnosing CTS; the sensory conduction study is known to be more sensitive than the motor conduction study in the early stage of the disease $[7,15]$. However, various studies reported controversial results, regarding which digit should be tested in order to increase the sensitivity and accuracy of the test. Aydin et al. [7] performed studies in comparing the median nerve conduction velocities of the 1st, 2nd, 3rd, and 4th digits on 818 hands of 525 CTS patients. This study reports that the 1st digit showed the highest frequency of decreased conduction velocity and that the 2 nd digit conduction

Table 5. Sensory nerve conduction velocity of each digit according to the severity of carpal tunnel syndrome

\begin{tabular}{ccccc}
\hline \multirow{2}{*}{ Digit } & \multicolumn{4}{c}{ Sensory nerve conduction velocity $(\mathbf{m} / \mathbf{s e c})$} \\
\cline { 2 - 5 } & Mild & Moderate & Severe & Total \\
\hline I & $39.46 \pm 14.87^{\text {a) }}$ & $30.22 \pm 13.41^{\text {a) }}$ & $20.85 \pm 19.81^{\text {a) }}$ & $30.12 \pm 19.91$ \\
II & $49.89 \pm 8.46^{\text {a,b) }}$ & $35.51 \pm 14.85^{\text {a) }}$ & $21.99 \pm 12.86^{\text {a) }}$ & $36.89 \pm 16.95$ \\
III & $43.56 \pm 11.58^{\text {a) }}$ & $33.19 \pm 12.29^{\text {a) }}$ & $24.12 \pm 24.07^{\text {a) }}$ & $35.26 \pm 14.53$ \\
IV & $42.11 \pm 16.21^{\text {a) }}$ & $30.36 \pm 11.67^{\text {a) }}$ & $15.99 \pm 10.32^{\text {a,b }}$ & $34.52 \pm 16.33$ \\
\hline
\end{tabular}

Values are presented as mean \pm standard deviation.

a) $\mathrm{p}<0.05$, comparison according to the severity in each digit. ${ }^{\text {b) }} \mathrm{p}<0.05$, comparison of digit in each degree.

Table 6. Onset latency of compound muscle action potentials according to the severity of CTS (unit=ms)

\begin{tabular}{|c|c|c|c|c|c|c|}
\hline \multirow{3}{*}{$\begin{array}{l}\text { Degree of } \\
\text { CTS }\end{array}$} & \multicolumn{6}{|c|}{ Recording muscles } \\
\hline & \multicolumn{2}{|c|}{ Abductor pollicis brevis } & \multirow[b]{2}{*}{ 2L } & \multirow[b]{2}{*}{ PI } & \multirow[b]{2}{*}{$\begin{array}{l}\text { Mean difference } \\
\text { between 2L-PI }\end{array}$} & \multirow[b]{2}{*}{$\begin{array}{c}\text { Rate of abnor } \\
\text { mality (\%) }\end{array}$} \\
\hline & Onset latency & $\begin{array}{l}\text { Rate of abnor- } \\
\text { mality (\%) }\end{array}$ & & & & \\
\hline Mild & $4.34 \pm 0.69$ & $60^{\mathrm{a})}$ & $4.36 \pm 0.73$ & \multirow{4}{*}{$2.98 \pm 0.37$} & $2.68 \pm 1.29$ & $81^{\mathrm{b})}$ \\
\hline Moderate & $5.05 \pm 0.68$ & 85 & $5.46 \pm 1.15$ & & $2.77 \pm 1.38$ & 84 \\
\hline Severe & $7.68 \pm 2.57^{\mathrm{a})}$ & 94 & $7.07 \pm 2.24^{\mathrm{a})}$ & & $4.09 \pm 3.87^{\mathrm{a})}$ & 92 \\
\hline Total & $5.47 \pm 1.93$ & 79 & $5.58 \pm 1.77$ & & $3.13 \pm 1.99$ & 85 \\
\hline
\end{tabular}

Values are presented mean \pm standard deviation. Criteria for abnormal onset latency of abductor pollicis brevis were 4.2 ms.

CTS, carpal tunnel syndrome; 2L, second lumbrical; PI, palmar interosseous.

${ }^{a)} \mathrm{p}<0.05$, comparison according to the severity in each recording muscles. ${ }^{\text {b) }} \mathrm{p}<0.05$, comparison between the recording muscles in each degree. 
velocity was relatively preserved. A study by TsaiweichaoShozawa et al. [15] states that the sensory branch of the median nerve to the 2nd digit and motor branch to the lumbrical muscle is relatively preserved in the late course of the disease. In the study performed with 55 CTS patients, Macdonell et al. [16] reported that the decrease in median conduction velocity was most prominent with the 1st digit and was less frequent with the 2 nd digit. However, Padua et al. [17] reported that there are significant decreases in conduction velocity at the 1st and 3rd digits without a significant difference between the two digits. Lauritzen et al. [18] also reported that there is no difference in the sensitivity of the test between the 1st and 3rd digit in a mild degree CTS. In a study by Terzis et al. [8] with 72 patients with mild degree CTS whose onset latency was shorter than $4.2 \mathrm{~ms}$ with APB recording, reported that the sensitivity of conduction studies on the 1 st, $2 \mathrm{nd}, 3 \mathrm{rd}$, and 4 th digits were be $61 \%, 22 \%, 50 \%$, and $88 \%$, respectively-the 4 th digit being the most useful in CTS diagnosis. Cioni et al. [19] compared the frequency of lowered conduction velocities between the digits, in a group of patients with clinical symptoms of CTS, where the frequencies were $64 \%, 80 \%$, and $92 \%$ in the 1 st, 2 nd, and 3rd digits, respectively. Conduction velocity was lowered in all of the patients in the 4 th digit.

In this study, comparisons of each digit according to the disease severity showed significant differences in the 2nd digit compared to the 1st, 3rd, and 4th digits for the mild, moderate, and severe groups. It seems that such a difference is due to the well preserved sensory branch to the 2nd digit in the mild degree group, which showed a difference even with the moderate group. Frequency of latency prolongation was significantly lower with the 2nd digit and SNAP amplitude ratio was also significantly higher compared to the 3rd and 4th digits. Frequency of abnormal values was also lower compared to the control group, though without statistical significance. The fact that among the 8 hands whose SNAPs were not evoked with the 1st, 3rd, and 4 th digits, the fact that 2 showed preserved SNAPs with the 2nd digit also supports these results. By contrast, the amplitude ratio was significantly low with the 4th digit, and the frequency of abnormal value was higher compared to the other digits in all the severities without statistical significance. An evaluation on the conduction velocity showed similar results. In the mild degree group, conduction velocity was relatively preserved with the 2 nd digit, and in the severe group, it was significantly decreased with the 4 th digit. In comparison of the conduction velocities despite the severity degree, it was decreased with the 1st digit, compared to the other digits.

Considering all the results from this study, it can be said that in the early stage of CTS, the 2nd digit is preserved. Differences in the degree of impairment between the digits according to the disease progression can be explained by fascicular arrangement of the median nerve under carpal tunnel $[16,20]$. In CTS, the median nerve injury occurs most severely at the distal end of carpal tunnel, just proximal to which the motor and sensory branches divide. In carpal tunnel, the median sensory branches to the 1st and 3rd digits lie in the antero-lateral side, branches to the 4th digit lie in the antero-medial side, and to the 2 nd digit lie in the postero-medial side. Due to such a fascicular arrangement, sensory branches to the 2nd digit, located in the posterior side, are less vulnerable to injury compared to other digits. Moreover, conduction study values are more preserved in the early stage, when compression or ischemia occurs in the carpal tunnel [7].

Despite the fact that the 4 th digit is severely affected by the disease progression, in clinical practice, physicians prefer to use the 2nd and 3rd digits over the 4th digit in median sensory conduction studies, due to small SNAPs caused by dual innervation of the median and ulnar nerve. However, considering the fact that the sensitivity of the 2nd digit in CTS diagnosis is not high $[7,15,16]$, and a study by Padua et al. [17] reported that the distalproximal distance ratios of the elbow and hand according to the course of the median nerves is most ideal in the 2nd and 3rd digits, it is most appropriate to use the 3rd digit for the active recording electrode in CTS diagnosis. In this study, diagnostic criteria for the peak latency was set to $3.7 \mathrm{~ms}$ for the $2 \mathrm{nd}$, 3rd, and 4th digits considering the same distance applied between the electrode and the stimulator. Considering different degrees of disease involvement in each digit, according to the disease progression, applying the same criteria can be a limitation of this study.

We also performed evaluations on the median motor conduction study. Among the median motor branches, the recurrent branch to the APB muscle is in a position to be more vulnerable to carpal tunnel compression than branches to the 1st and 2nd lumbrical muscles. Sunderland [21] discovered that branch to the lumbrical muscle is positioned postero-medially to the APB branch at 37 
$\mathrm{mm}$ distal to the radial styloid process of the wrist, and at the $20 \mathrm{~mm}$ distal point, it is positioned relatively anterior compared to the distal part, yet still posterior to the APB branch. They also reported that the sensory branch to the 2nd digit is positioned relatively posterior to the lumbrical muscle motor branches. Tsaiweichao-Shozawa et al. [15] reported that due to such arrangements of nerve fascicles, branches to the 2nd digit and lumbrical muscle are relatively more preserved in carpal tunnel compression, and that a correlation exists between the conduction study values of the two branches. Therefore, various studies exist on the clinical usefulness of lumbrical muscle recording for CTS diagnosis. Sheean et al. [6] claimed that though using lumbrical muscle may not increase the sensitivity of electrodiagnostic study, measuring lumbrical-interosseous muscle latency differences can be useful. Boonyapisit et al. [10] reported that in moderate degree CTS, a lumbrical muscle recording conduction study is useful in the dfferential and accurate diagnoses.

In this study, latency prolongation with APB muscle recording was significantly lower in frequency than lumbrical-interosseous latency differences in the mild degree group, which is similar to a previous study by Sheean et al. [6] The reason for such result is that in the early process of CTS, demyelination is the main pathology of the disease, so when the damage is minimal, latency may appear within normal range. However, compared to the latency of the ulnar nerve, which does not pass through the carpal tunnel, latencies of the median nerve is relatively prolonged and the latency difference can be significant, which makes lumbrical-interosseous latency differences more sensitive than the latency recorded from the APB muscle. As the disease progresses, the pathophysiology of the disease changes and due to its anatomically favorable position, the branch to the lumbrical muscle is less affected by the conduction block or axonal injury, and is relatively preserved in the conduction study. In this study, from the 4 digits with unevoked APB recorded CMAPs, and from the 8 digits with unevoked SNAPs, lumbrical muscle recording CMAPs were all obtained. These results show that the lumbrical-interosseous latency difference is a tool for increasing sensitivity in CTS diagnosis, and consistent with previous studies, as the disease progress, lumbrical muscle is relatively preserved in severe degree CTS.

In conclusion, this study shows that the 4 th digit SNAP is the most severely affected in CTS, but the 2nd digit SNAP is relatively spared, and that lumbrical recorded median CMAP is spared in the severe degree CTS group. Considering its sensitivity and specificity, the 3rd digit is commonly used in clinical practice for electrodiagnostic study in CTS. However, in severe patients, using the SNAP recorded on the 2nd digit or the CMAP recorded on the lumbrical muscle, which are relatively spared even in the late stage of the disease, may help in diagnosing CTS.

\section{CONFLICT OF INTEREST}

No potential conflict of interest relevant to this article was reported

\section{REFERENCES}

1. Quality Standards Subcommittee of the American Academy of Neurology. Practice parameter for carpal tunnel syndrome (summary statement). Neurology 1993;43:2406-9.

2. Atroshi I, Gummesson C, Johnsson R, Ornstein E, Ranstam J, Rosen I. Prevalence of carpal tunnel syndrome in a general population. JAMA 1999;282:153-8.

3. Jablecki CK, Andary MT, So YT, Wilkins DE, Williams FH. Literature review of the usefulness of nerve conduction studies and electromyography for the evaluation of patients with carpal tunnel syndrome. AAEM Quality Assurance Committee. Muscle Nerve 1993;16:1392-414.

4. Bernstein WJ. The electrodiagnosis of carpal tunnel syndrome. Muscle Nerve 1999;22:139-40.

5. Jablecki CK, Andary MT, Floeter MK, Miller RG, Quartly CA, Vennix MJ, et al. WITHDRAWN: Second AAEM literature review of the usefulness of nerve conduction studies and needle electromyography for the evaluation of patients with carpal tunnel syndrome. Muscle Nerve 2002 Jun 11 [Epub].

6. Sheean GL, Houser MK, Murray NM. Lumbricalinterosseous latency comparison in the diagnosis of carpal tunnel syndrome. Electroencephalogr Clin Neurophysiol 1995;97:285-9.

7. Aydin G, Keles I, Ozbudak Demir S, Baysal AI. Sensitivity of median sensory nerve conduction tests in digital branches for the diagnosis of carpal tunnel syndrome. Am J Phys Med Rehabil 2004;83:17-21. 
8. Terzis S, Paschalis C, Metallinos IC, Papapetropoulos T. Early diagnosis of carpal tunnel syndrome: comparison of sensory conduction studies of four fingers. Muscle Nerve 1998;21:1543-5.

9. Werner RA, Andary M. Carpal tunnel syndrome: pathophysiology and clinical neurophysiology. Clin Neurophysiol 2002;113:1373-81.

10. Boonyapisit K, Katirji B, Shapiro BE, Preston DC. Lumbrical and interossei recording in severe carpal tunnel syndrome. Muscle Nerve 2002;25:102-5.

11. Johnson EW, Sipski M, Lammertse T. Median and radial sensory latencies to digit I: normal values and usefulness in carpal tunnel syndrome. Arch Phys Med Rehabil 1987;68:140-1.

12. Preston DC, Logigian EL. Lumbrical and interossei recording in carpal tunnel syndrome. Muscle Nerve 1992;15:1253-7.

13. Lee HJ, Kwon HK. Electrophysiologic classification of severity of carpal tunnel syndrome. J Korean Assoc EMG-Electrodiagn Med 2004;6:1-3.

14. Pyun SB, Kwon HK, Lee HJ. How to deal with the latency of unobtainable responses in the statistical analysis. J Korean Acad Rehabil Med 1998;22:1056-9.

15. Macdonell RA, Schwartz MS, Swash M. Carpal tunnel syndrome: which finger should be tested? an analysis of sensory conduction in digital branches of the median nerve. Muscle Nerve 1990;13:601-6.

16. Tsaiweichao-Shozawa Y, Sonoo M, Shimizu T. Patterns of nerve conduction abnormalities in severe carpal tunnel syndrome. J Clin Neurophysiol 2008;25:281-6.

17. Padua L, LoMonaco M, Gregori B, Valente EM, Padua R, Tonali P. Neurophysiological classification and sensitivity in 500 carpal tunnel syndrome hands. Acta Neurol Scand 1997;96:211-7.

18. Lauritzen M, Liguori R, Trojaborg W. Orthodromic sensory conduction along the ring finger in normal subjects and in patients with a carpal tunnel syndrome. Electroencephalogr Clin Neurophysiol 1991;81:18-23.

19. Cioni R, Passero S, Paradiso C, Giannini F, Battistini N, Rushworth G. Diagnostic specificity of sensory and motor nerve conduction variables in early detection of carpal tunnel syndrome. J Neurol 1989;236:208-13.

20. Kuntzer T. Carpal tunnel syndrome in 100 patients: sensitivity, specificity of multi-neurophysiological procedures and estimation of axonal loss of motor, sensory and sympathetic median nerve fibers. J Neurol Sci 1994;127:221-9.

21. Sunderland S. The intraneural topography of the radial, median and ulnar nerves. Brain 1945;68:243-99. 